\title{
The child perception questionnaire is valid for malocclusions in the United Kingdom
}

\author{
Kevin O'Brien, ${ }^{a}$ Jean L. Wright, ${ }^{b}$ Frances Conboy, ${ }^{b}$ Tatiana Macfarlane, ${ }^{c}$ and Nicky Mandall ${ }^{d}$ \\ Manchester, United Kingdom
}

Introduction: The purpose of this study was to validate the child perception questionnaire $\left(C P Q_{11-14}\right)$ with a sample of schoolchildren in Greater Manchester, United Kingdom. Methods: We made a longitudinal survey of children from 1999 to 2002, using the index of orthodontic treatment need (IOTN) at baseline when the children were 11 to 12 years old, the $C P Q_{11-14}$, and their uptake of orthodontic treatment 3 years later. Results: $\mathrm{CPQ}_{11-14}$ scores corresponded to differences in IOTN scores. These were related to the child's emotional and social well-being. Regression analysis showed that $C P Q_{11-14}$ scores were higher for girls, for higher grades of the dental health component of the IOTN, and for children who thought that their teeth needed straightening. Conclusions: $\mathrm{CPQ}_{11-14}$ has acceptable reliability and validity, and is likely to be a useful measure for orthodontic trials. The impact of malocclusion on a child's quality of life might be substantial. (Am J Orthod Dentofacial Orthop 2006;129:536-40)

$\mathbf{I}$ n this article, we outline a study to evaluate the validity of the child perception questionnaire $\left(\mathrm{CPQ}_{11-14}\right)$ as a measure of the impacts of malocclusion on children's oral health. ${ }^{1}$

Traditionally, the aims of orthodontic treatment are to improve dental health and esthetics, thereby improving a patient's sociopsychological well-being. Unfortunately, when these benefits are critically evaluated, research has suggested that they are not clearcut. For example, a large-scale observational longitudinal study showed that only the severe traits of malocclusion, such as large overjets $(>6 \mathrm{~mm})$, traumatic overbites, and impacted teeth have deleterious effects on dental health. $^{2}$

The association of quality of life with malocclusion has not been extensively studied for its major effects. The measurement of entry criteria or effectiveness of orthodontic treatment has been based on morphologic change, by using, for example, occlusal indexes or cephalometric measurements. Unfortunately, these outcome measures reflect only the professional viewpoint, and not that of the patient or the consumer of care. These types of measurements have also been criticized

From the University of Manchester, Manchester, United Kingdom.

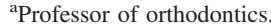

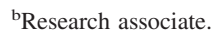

${ }^{\mathrm{c}}$ Lecturer in biostatistics.

${ }^{\mathrm{d}}$ Senior lecturer in orthodontics.

Reprint requests to: Dr Kevin O'Brien, University of Manchester, School of Dentistry, Higher Cambridge St, Manchester M15 6FH, United Kingdom; e-mail, kevin.obrien@man.ac.uk.

Submitted, July 2004; revised and accepted, October 2004 $0889-5406 / \$ 32.00$

Copyright (C) 2006 by the American Association of Orthodontists. doi:10.1016/j.ajodo.2004.10.014 because they are not always relevant to consumers' functional or social requirements. Importantly, the use of this measurement is particularly relevant to orthodontic treatment because the demarcation between acceptable and unacceptable occlusion is influenced by idiosyncratic judgment. This is illustrated by our recent studies showing that some referred patients reject orthodontic treatment for professionally perceived handicapping malocclusions, and others seek treatment for minor deviations. ${ }^{3}$

Therefore, if we are to develop indicators of orthodontic treatment need and success from the consumer's viewpoint, we should consider impairment, disability, and handicap that are integral to other sociodental indicators. For example, a child with prominent incisors (an impairment) might be teased at school, become embarrassed (psychological disability), and avoid contact with peers (social disability). As a result, a measure to evaluate treatment need and effectiveness should include not only normative assessment but also psychological and social dimensions. These measures have been developed for other dental problems; they are called sociodental indicators. ${ }^{4}$

Sociodental indicators have been developed to assess oral health quality of life for adults but not, until recently, for children. ${ }^{4-8}$ This is partly because of complex conceptual and methodological issues involved in the construction of self-reporting healthstatus indicators for children. ${ }^{9,10}$ This issue has, however, been resolved by the development of the child perceptions questionnaire $\left(\mathrm{CPQ}_{11-14}\right)$, which is an oral-health quality-of-life assessment for children aged 11 to 14 years. It was developed to apply to 
children with various dental, oral, and orofacial disorders, and has been shown to have adequate validity and reliability. ${ }^{1}$

The aims of this investigation were to validate the $\mathrm{CPQ}_{11-14}$ for malocclusion on a population of children in the United Kingdom, and to evaluate whether malocclusion has an influence on the $\mathrm{CPQ}_{11-14}$.

Our null hypotheses were that there are no differences between $\mathrm{CPQ}_{11-14}$ scores and need for orthodontic treatment as measured by the index of orthodontic treatment need (IOTN), ${ }^{11}$ and that these differences are not influenced by the child's initial need for treatment at 11 years old, socioeconomic status, age, and sex.

\section{MATERIAL AND METHODS}

We used health-district dentist lists and centrally held data to calculate the ratios of dentists and orthodontists to children aged 10 to 14 years.

Fifteen schools were randomly sampled in the Greater Manchester and Lancashire regions of the United Kingdom to reflect high and low orthodontic treatment provision. This study was part of a larger investigation of factors influencing the uptake of orthodontic treatment; data had been collected from 525 children when they were aged 11 to 12 years. Of these, $325(62 \%)$ children were revisited 3 years later to evaluate treatment uptake. Children who were undergoing orthodontic treatment at the first visit were excluded from the follow-up.

We collected the following baseline data.

- Demographic information: age, sex, and socioeconomic status measured with the Townsend score. ${ }^{12}$ This is a population-based measure of social deprivation that is calculated by using United Kingdom census (1991) data derived from zip codes. A high score represents greater levels of deprivation.

- Normative measures of treatment need: IOTN aesthetic component (AC) and dental health component (DHC) recorded by calibrated examiners (K.O.B. and N.M.).

- Consumer measures: children's self-perceived IOTN AC scores. ${ }^{13}$

Three years later, the same schools were revisited to identify children who had received, or were on a waiting list for, orthodontic treatment.

At the follow-up, children who were absent at the visit were sent the questionnaire and asked to return it. Participants were asked whether they had received orthodontic treatment, were currently undergoing treatment, or were on a waiting list to receive treatment.

They completed the $\mathrm{CPQ}_{11-14}$; children who were absent at the visit were sent the questionnaire and asked to return it.

The $\mathrm{CPQ}_{11-14}$ is part of the child oral-health quality-of-life instrument. ${ }^{1}$ This measure was recently developed to measure the oral-health quality of life of children aged 11 to 14 years who have various dental, orthodontic, and orofacial conditions. This initial study shows that the questionnaire has excellent validity and reliability, and also suggested that the impact of oral and orofacial conditions on children's functional and psychosocial well-being is substantial.

The questionnaire consists of 36 items that are grouped into 4 health domains: oral symptoms, functional limitations, emotional well-being, and social well-being.

The development process that was adopted ensured that these items contained options that not only were the most frequent but also created the most concern for children.

Each question asks about the frequency of events in the last 3 months; the response options were "never," "once or twice," "sometimes," "often," and "every day or almost every day." In addition, the questionnaire contained global ratings of the child's oral health and the extent to which the condition affected oral wellbeing. These ratings had a 5-point scale from "excellent" to "poor."

\section{Statistical methods}

Statistical analysis was carried out with SPSS 10.0 (SPSS, Chicago, Ill) and Stata 7.0 (Stata, College Station, Tex) statistical software packages.

We determined the internal consistency of the $\mathrm{CPQ}_{11-14}$ by measuring interitem correlations and the Cronbach alpha statistic; this produced an estimate of reliability based on all correlations between all items in the questionnaire.

The total scores for each subscale (oral symptoms, functional limitation, emotional well-being, and social well-being) and total oral-health score were calculated as the sum of the scores of each item on the questionnaire. Because these scores were not normally distributed, the Mann-Whitney U test and the Kruskal-Wallis tests were used to compare the groups.

We categorized the components of IOTN and total questionnaire scores using the median of distribution of the scores. We then used logistic regression (considering clustering within schools) to determine the simultaneous effect of factors on total questionnaire score. This enabled us to calculate a subject's risk of having a high $\mathrm{CPQ}_{11-14}$ score as a function of sex, $\mathrm{AC}$ score, DHC score, IOTN score, and whether the subject had received orthodontic treatment. This is expressed as the 
Table I. $\mathrm{CPQ}_{11-14}$ scores by socioeconomic and baseline factors

\begin{tabular}{|c|c|c|c|c|c|c|}
\hline Factor (baseline) & $\begin{array}{l}\text { Number } \\
\text { in group }\end{array}$ & $\begin{array}{c}\text { Oral symptoms } \\
\text { median }(I Q R)\end{array}$ & $\begin{array}{c}\text { Functional limitations } \\
\text { median }(I Q R)\end{array}$ & $\begin{array}{l}\text { Emotional well-being } \\
\text { median }(I Q R)\end{array}$ & $\begin{array}{l}\text { Social well-being } \\
\text { median }(I Q R)\end{array}$ & $\begin{array}{c}\text { Total score } \\
\text { median }(I Q R)\end{array}$ \\
\hline \multicolumn{7}{|l|}{ Sex } \\
\hline $\mathrm{M}$ & 158 & $10(4)$ & $13(5)$ & $11(5)$ & $15(6)$ & $50(14)$ \\
\hline $\mathrm{F}$ & 167 & $10(3)$ & $14(6)$ & $13(8)$ & $15(5)$ & $54(19)$ \\
\hline Mann-Whitney U test & & $P=.168$ & $P=.007$ & $P<.001$ & $P=.193$ & $P=.003$ \\
\hline \multicolumn{7}{|l|}{$\begin{array}{l}\text { Socioeconomic status } \\
\text { (Townsend) (baseline) }\end{array}$} \\
\hline 1 (low) $(-5.72,-1.29)$ & 76 & $10(3)$ & $14(5)$ & $12(5)$ & $15(4)$ & $52(15)$ \\
\hline $2(-0.70,1.65)$ & 75 & $10(4)$ & $13(5)$ & $12(7)$ & $15(4)$ & $50(14)$ \\
\hline $3(1.81,5.87)$ & 76 & $10(3)$ & $14(6)$ & $12(8)$ & $15(7)$ & $53(15)$ \\
\hline 4 (high) $(6.05,12.07)$ & 75 & $11(4)$ & $14(7)$ & $12(5)$ & $15(6)$ & $52(20)$ \\
\hline Kruskal-Wallis test & & $P=.278$ & $P=.720$ & $P=.866$ & $P=.865$ & $P=.866$ \\
\hline \multicolumn{7}{|l|}{ Child's own AC assessment } \\
\hline $1-3$ & 192 & $10(4)$ & $13(5)$ & $12(6)$ & $15(5)$ & $51(16)$ \\
\hline $4-10$ & 133 & $10(3)$ & $14(6)$ & $12(6)$ & $16(7)$ & $54(16)$ \\
\hline Mann-Whitney U test & & $P=.409$ & $P=.281$ & $P=.021$ & $P=.003$ & $P=.024$ \\
\hline \multicolumn{7}{|l|}{ AC score } \\
\hline $1-5$ & 174 & $10(3)$ & $13(5)$ & $12(6)$ & $15(5)$ & $51(15)$ \\
\hline $6-10$ & 151 & $10(4)$ & $14(6)$ & $13(6)$ & $15(6)$ & $53(17)$ \\
\hline Mann-Whitney U test & & $P=.017$ & $P=.512$ & $P=.034$ & $P=.087$ & $P=.040$ \\
\hline \multicolumn{7}{|l|}{ DHC score } \\
\hline $2-3$ & 180 & $10(4)$ & $13(5)$ & $12(6)$ & $15(5)$ & $51(16)$ \\
\hline $4-5$ & 145 & $10(3)$ & $14(6)$ & $13(6)$ & $16(6)$ & $54(16)$ \\
\hline Mann-Whitney U test & & $P=.122$ & $P=.340$ & $P=.116$ & $P=.016$ & $P=.027$ \\
\hline
\end{tabular}

$I Q R$, Interquartile range, difference between 75 th and 25 th percentiles.

odds ratio (OR) and 95\% confidence interval (CI) for each factor.

\section{RESULTS}

The 325 children, born in 1986 and 1987, included 158 boys $(48 \%)$ and 167 girls $(52 \%)$. Most (296, or $91 \%$ ) reported good, very good, or excellent health of teeth, lips, jaws, and mouth. However, 218 (67.1\%) reported some impact on their quality of life overall.

Most (223, or 69\%) had not received orthodontic treatment, $18(5 \%)$ had orthodontic treatment in the past, $45(14 \%)$ were undergoing treatment at the time of questionnaire completion, and $39(12 \%)$ were on a waiting list for orthodontic treatment; 127 (39\%) thought that their teeth needed straightening.

The Cronbach alpha calculations for all 37 items of the questionnaire produced a reliability coefficient of 0.90, indicating strong internal consistency. The alpha score remained at 0.90 for each item, showing that no item was adversely affecting the internal consistency of the scale-ie, the items were measuring the same construct (oral-health quality of life). In addition, itemtest correlations ranged from 0.24 to 0.68 , showing moderate correlations. Item-retest correlations represent the correlation coefficients when that item was correlated with the scores from all other items; these ranged from 0.21 to 0.65 . The lowest correlations were observed for bad breath, breathe through the mouth, and difficulty drinking with a straw. The highest correlations were noted for being upset and feeling nervous or afraid. However, the Cronbach alpha did not change when any of the items were dropped.

Descriptive data on the children and the $\mathrm{CPQ}_{11-14}$ domains are shown in Table I, along with information on the relevant statistical analysis. This initial data analysis showed higher $\mathrm{CPQ}_{11-14}$ scores for girls than boys, and the scores were unrelated to socioeconomic status. Interestingly, all IOTN scores at baseline had an influence on total $\mathrm{CPQ}_{11-14}$; the greater the IOTN score, the higher the oral impact. When we considered the domains of the $\mathrm{CPQ}_{11-14}$, there were differences in emotional well-being for the $\mathrm{AC}$ scores and social well-being for all IOTN scores, but there was no effect on oral symptoms and functional limitations.

The data collected at the follow-up stage are given in Table II. They showed that children who were on a waiting list or had received orthodontic treatment reported higher $\mathrm{CPQ}_{11-14}$ scores for the total score and the domains of functional limitation, emotional well-being, and social well-being. Importantly, if a child thought that his or her teeth needed straightening, the $\mathrm{CPQ}_{11-14}$ score was higher for the total and all domains.

The final logistic regression analysis model, which 
Table II. $\mathrm{CPQ}_{11-14}$ scores by follow-up factors

\begin{tabular}{|c|c|c|c|c|c|c|}
\hline Factor (follow-up) & $\begin{array}{l}\text { Number in } \\
\text { group }\end{array}$ & $\begin{array}{l}\text { Oral symptoms } \\
\text { median }(I Q R)\end{array}$ & $\begin{array}{c}\text { Functional limitations } \\
\text { median }(I Q R)\end{array}$ & $\begin{array}{l}\text { Emotional well-being } \\
\text { median }(I Q R)\end{array}$ & $\begin{array}{l}\text { Social well-being } \\
\text { median }(I Q R)\end{array}$ & $\begin{array}{c}\text { Total score } \\
\text { median }(I Q R)\end{array}$ \\
\hline \multicolumn{7}{|l|}{$\begin{array}{l}\text { Orthodontic treatment } \\
\text { (follow-up) }\end{array}$} \\
\hline Never & 223 & $10(3)$ & $13(5)$ & $12(6)$ & $15(5)$ & $51(15)$ \\
\hline Past & 18 & $11(5)$ & $14(10)$ & $15(11)$ & $17(11)$ & $60(19)$ \\
\hline Current & 45 & $10(3)$ & $16(4)$ & $13(5)$ & $18(6)$ & $58(15)$ \\
\hline On waiting list & 39 & $10(4)$ & $14(5)$ & $12(8)$ & $15(3)$ & $50(18)$ \\
\hline Kruskal-Wallis test & & $P=.228$ & $P=.0003$ & $P=.001$ & $P=.0007$ & $P=.0009$ \\
\hline \multicolumn{7}{|l|}{$\begin{array}{l}\text { Do you think your teeth } \\
\text { need straightening? }\end{array}$} \\
\hline No & 198 & $10(4)$ & $13(6)$ & $11(5)$ & $14(4)$ & $50(14)$ \\
\hline Yes & 127 & $10(4)$ & $15(7)$ & $14(8)$ & $16(6)$ & $56(21)$ \\
\hline Mann-Whitney U test & & $P=.0012$ & $P=.001$ & $P<.001$ & $P<.001$ & $P<.001$ \\
\hline
\end{tabular}

$I Q R$, Interquartile range, difference between 75 th and 25 th percentile.

Table III. Details of logistic regression analysis on total $\mathrm{CHQ}_{11-14}$ (categorized by median)

\begin{tabular}{|c|c|c|c|}
\hline Factor & $\begin{array}{l}\text { Number in } \\
\text { group }\end{array}$ & $\begin{array}{l}\text { Full model* } \\
\text { OR }(95 \% \text { CI) }\end{array}$ & $\begin{array}{c}\text { Final model (stepwise selection)* } \\
\text { OR }(95 \% \text { CI })\end{array}$ \\
\hline \multicolumn{4}{|l|}{ Sex } \\
\hline M & 158 & 1.00 & 1.00 \\
\hline $\mathrm{F}$ & 167 & $2.14^{\dagger}(1.37,3.36)$ & $2.19(1.37,3.50)$ \\
\hline \multicolumn{4}{|c|}{ Child's own AC assessment (baseline) } \\
\hline $1-3$ & 192 & 1.00 & - \\
\hline $4-10$ & 133 & $1.08(0.66,1.76)$ & \\
\hline \multicolumn{4}{|c|}{ Normative orthodontic treatment need (AC) (baseline) } \\
\hline $1-5$ & 174 & 1.00 & - \\
\hline $6-10$ & 151 & $1.07(0.53-2.16)$ & \\
\hline \multicolumn{4}{|c|}{ Normative orthodontic treatment need (DHC) (baseline) } \\
\hline $2-3$ & 180 & 1.00 & 1.00 \\
\hline $4-5$ & 145 & $1.48(0.90-2.44)$ & $1.67(1.07,2.62)$ \\
\hline \multicolumn{4}{|c|}{ Orthodontic treatment (follow-up) } \\
\hline Never & 223 & 1.00 & - \\
\hline Past & 18 & $2.44(0.78,7.67)$ & \\
\hline Current & 45 & $1.60(0.61,4.23)$ & \\
\hline On waiting list & 39 & $0.85(0.41,1.74)$ & \\
\hline \multicolumn{4}{|c|}{ Do you think your teeth need straightening? } \\
\hline No & 198 & 1.00 & 1.00 \\
\hline Yes & 127 & $1.71(0.92,3.19)$ & $2.08(1.18,3.64)$ \\
\hline
\end{tabular}

*Standard errors adjusted for clustering within schools.

${ }^{\dagger}$ Girls were more likely to have high (above median) $\mathrm{CHQ}_{11-14}$ scores than boys.

took into account the possible effect of confounding variables, is given in Table III. It showed that $\mathrm{CPQ}_{11-14}$ scores were higher for girls, for higher grades of the DHC, and for children who thought that their teeth needed straightening. Importantly, there was no effect for AC scores.

\section{DISCUSSION}

The most important finding of this study was that the $\mathrm{CPQ}_{11-14}$ scores corresponded to differences in need for orthodontic treatment as measured by the IOTN. In addition, when we analyzed the domains of
$\mathrm{CPQ}_{11-14}$, it appeared that these differences were mostly concerned with a child's emotional and social well-being. This is logical when we consider that the most common reason for seeking orthodontic treatment is to correct dental esthetics. It is unlikely that oral symptoms (bleeding gums, pain in the teeth) and functional limitations (speech problems, difficulty in mouth opening, and eating) arise from malocclusion.

The data from the regression analysis also reinforced these findings when we considered that there were differences between sex and those who did or did not want orthodontic treatment. These data suggest that 
the $\mathrm{CPQ}_{11-14}$ has validity in evaluating the effect of malocclusion on a child's oral-health quality of life. This reinforces the conclusions of the developers of this measure when they used it on children at pediatric dentistry and orthodontic clinics in Canada. ${ }^{1}$

The questionnaire showed strong internal consistency in our sample. This is consistent with the value of the Cronbach alpha of 0.91 reported by Jokovic et al. ${ }^{1}$

This study also evaluated the effect of malocclusion on the $\mathrm{CPQ}_{11-14}$ measure; this was carried out as part of its development. In this study, they gathered $\mathrm{CPQ}_{11-14}$ scores for groups of children who were attending pediatric dental, orthodontic, and orofacial-anomalies clinics. This showed differences between the 3 groups of children. It is difficult to compare these results with our sample because of differences in sample size and setting, but it appears that the scores from the United Kingdom sample were considerably greater than those of the Canadian sample. This might be because of cultural differences, or perhaps because the children in the Canadian sample actually received treatment for their orthodontic problems, whereas most of our sample did not access orthodontic care.

Interestingly, girls reported higher impacts than boys; this might be due to the commonly reported sex effect on the perceptions of health care and orthodontic treatment. For example, other orthodontic studies have suggested that girls have greater esthetic concerns than boys, and girls are more likely to seek and receive orthodontic treatment. ${ }^{3,14}$

In this investigation, we used IOTN data collected several years previously when the children were 11 years old. The data reflected the point when most subjects in our initial sample were likely to enter orthodontic care. Furthermore, it has been shown that IOTN scores remain stable over time in a child population. ${ }^{15}$

\section{CONCLUSIONS}

1. The $\mathrm{CPQ}_{11-14}$ questionnaire has acceptable validity and reliability, and is likely to be a useful measure in orthodontic clinical trials.
2. The impact of malocclusion on a child's quality of life can be substantial.

We are grateful to the staff and the pupils of the schools that took part in this investigation.

\section{REFERENCES}

1. Jokovic A, Locker D, Stephens M, Kenny D, Tompson B, Guyatt G. Validity and reliability of a questionnaire for measuring child oral-health related quality of life. J Dent Res 2002;81:459-63.

2. Shaw WC, Richmond S, O'Brien KD. Quality control in orthodontics: risk/benefit analysis. Br Dent J 1991;170:33-7.

3. O'Brien KD, Fox N, McComb JL, Wright J. Factors influencing the uptake of orthodontic treatment. Br J Orthod 1996;23:331-4.

4. Slade GD, Spencer AJ. Development and evaluation of the oral health impact profile. Community Dent Health 1994;11:3-11.

5. Cushing AM, Sheiham A, Maizels J. Developing sociodental indicators-the social impact of dental disease. Community Dent Health 1986;3:3-17.

6. Atchinson KA, Dolan TA. Development of the geriatric oral health assessment index. J Dent Educ 1990;54:680-7.

7. Locker D, Miller Y. Subjectively reported oral health status in an adult population. Community Dent Oral Epidemiol 1994; 22:425-30.

8. Leao A, Sheiham A. The development of a socio-dental measure of dental impacts on daily living. Community Dent Health 1996;13:22-6.

9. Pantell RH, Lewis CC. Measuring the impact of medical care on children. J Chronic Dis 1987;40(Suppl):99-115.

10. Pal DK. Quality of life assessment in children: a review of conceptual and methodological issues in multidimensional health status measures. J Epidemiol Community Health 1996;50:391-6.

11. Brook PH, Shaw WC. The development of an index of orthodontic treatment priority. Eur J Orthod 1989;3:309-20.

12. Townsend P. Deprivation. J Soc Policy 1987;16:125-46.

13. Mandall NA, McCord JF, Blinkhorn AS, Worthington HV, O'Brien KD. Perceived aesthetic impact of malocclusion and oral self-perception in 14-15 year-old Asian and Caucasian children in Greater Manchester. Eur J Orthod 1999; 21:175-83.

14. Burden D. The influence of social class, gender and peers on the uptake of orthodontic treatment. Eur J Orthod 1995;17: 199-203.

15. Cooper S, Mandall NA, Dibiase D, Shaw WC. The reliability of the index of orthodontic treatment need over time. J Orthod 2000;27:47-54. 